\title{
Annexin 5 Inhibits Thyrotropin Releasing Hormone (TRH) Stimulated Prolactin Release in the Primary Culture of Rat Anterior Pituitary Cells
}

\author{
Mitsumori KAWAMINAMI, AKIO SENDA, SEISHI ETOH, Hiroko MIYAOKA, SHIRO KURUSU \\ AND INORU HASHIMOTO
}

Laboratory of Veterinary Physiology, School of Veterinary Medicine and Animal Sciences, Kitasato University, Towada, Aomori 034-8628, Japan

\begin{abstract}
Annexin 5, a novel calcium-phospholipid binding protein, is thought to be involved in hormone secretion by the anterior pituitary gland. Gonadotropin releasing hormone stimulates annexin 5 synthesis, which, in turn, enhances gonadotoropin secretion. On the other hand, annexin 5 was shown to inhibit prolactin release in vitro. To understand the nature of the opposing effects of annexin 5 on these two major pituitary hormones, the present study examines the inhibitory effect of annexin 5 on prolactin release in relation to thyrotropin stimulating hormone (TRH) using primary cultures of anterior pituitary cells of adult female rats. While recombinant rat annexin 5 was found to have little effect on basal prolactin release, it significantly inhibited TRH-stimulated prolactin release. Addition of specific anti-annexin 5 serum to the culture increased basal prolactin release in a concentration dependent manner, and no further increase in prolactin release was observed following application of TRH in the presence of anti-annexin 5. The enhanced basal prolactin release induced by anti-annexin 5 was reversed by the simultaneous administration of indomethacin, an inhibitor of cyclooxygenase. These results demonstrate that endogenous pituitary annexin 5 exerts an inhibitory effect on prolactin release and suggest that this is attained by suppression of eicosanoid synthesis in vitro.
\end{abstract}

Key words: Annexin 5, Prolactin, Pituitary, TRH, Indomethacin

(Endocrine Journal 51: 349-354, 2004)

\begin{abstract}
ANNEXIN 5 is a member of the annexin family of proteins all of which bind phospholipids in a calcium dependent-manner [1]. Annexin 5 was first identified as a protein with structural similarity to annexin 1 , a mediator of the anti-inflammatory activity of glucocorticoids via inhibition of phospholipase $\mathrm{A}_{2}[2,3]$ and an inhibitor of blood coagulation [4]. Annexin 5 also shows protein kinase $\mathrm{C}$ inhibitory activity [5] and it forms calcium channels on phospholipid membranes [6]. Although the biochemical properties of annexinfamily proteins suggest roles in significant cell func-

Received: January 9, 2004

Accepted: March 29, 2004

Correspondence to: Dr. Mitsumori KAWAMINAMI, Laboratory of Veterinary Physiology, School of Veterinary Medicine and Animal Sciences, Kitasato University, Towada, Aomori 034-8628, Japan
\end{abstract}

tions, the function of these proteins in physiological processes is still obscure [7]. We previously demonstrated that annexin 5 is synthesized in the anterior pituitary gland [8] and later found that it is produced by pituitary gonadotropes under the regulation of gonadotropin releasing hormone (GnRH) [9-13]. As annexin 5 augments gonadotropin secretion in vitro [13] and antisense oligodeoxynucleotide to annexin 5 mRNA retards luteinizing hormone release by $\mathrm{GnRH}$, annexin 5 is thought to mediate at least part of the action of GnRH on pituitary gonadotropes [13].

We found that annexin 5 distributes also in lactotropes and other pituitary cells $[11,14]$, although the intensity is less than that of the gonadotropes and it has yet to be determined whether annexin 5 is synthesized in these cell species or not. Annexin 5 was shown to inhibit prolactin release, even though the degree of inhibition was not very high in primary pituitary cell 
cultures [14]. Prolactin is a major pituitary hormone and its secretion is negatively regulated by hypothalamic dopamine [15]. Prolactin secretion is augmented in lactation, in acute stress, in the luteal phase, and in the afternoon of the proestrous day. Its secretion is usually accompanied by suppression of gonadotropin secretion [16]. On the other hand, prolactin secretion is usually low when the secretion of gonadotropin is high [17]. It is of interest that annexin 5 has been shown to exert opposite effects on gonadotropes and lactotropes in culture. It is thus important to clarify the mechanism of annexin 5 inhibition of prolactin secretion. In the present study, we examined the effect of annexin 5 on prolactin release in relation to TRH, a major prolactin stimulating hormone [18].

\section{Materials and Methods}

\section{Reagents}

Recombinant rat annexin 5 was synthesized in our laboratory according to a previously reported protocol [19]. Rabbit antiserum against recombinant rat annexin 5 (UM-1) was raised in our laboratory. By SDS-PAGE and Western blotting, the antiserum was confirmed to recognize only a single $36 \mathrm{kDa}$ protein, annexin 5, out of total rat pituitary proteins. TRH and indomethacin were purchased from Sigma (St. Louis, MO). Dulbecco's Modified Eagle medium (DMEM), essential amino acid solution, trypsin and trypsin inhibitor were obtained from Invitrogen (Carlsbad, CA).

\section{Primary culture of anterior pituitary cells}

Experiments were performed on adult female Wistar Imamichi rats bred in our laboratory. All experiments using laboratory animals were performed according to protocols approved by The Committee of Animal Care and Use of Kitasato University. Rats were maintained in light $(5: 00-19: 00 \mathrm{hr})$ and temperature $\left(23 \pm 3^{\circ} \mathrm{C}\right)$ controlled rooms, and allowed access to food and tap water ad libitum. Primary cultures of rat anterior pituitary cells were prepared as reported previously [20]. Briefly, anterior pituitary glands from estrous cycling rats regardless of their stages were collected shortly after decapitation and dispersed with trypsin. Cells were maintained in DMEM supplemented with $10 \%$ fetal calf serum (FCS), streptomycin $(100 \mu \mathrm{g} / \mathrm{ml})$ and peni- cillin $(100 \mathrm{U} / \mathrm{ml})$. Two days after dissociation, the medium was changed to DMEM without FCS and for a three-hour preincubation before each experiment.

\section{Experiments}

Pituitary cells were incubated with a various concentrations of recombinant annexin 5 for three hours to see the effect on prolactin release. After three hours culture medium was collected and stored at $-80^{\circ} \mathrm{C}$ until the assay of rat prolactin. The effect of annexin $5(1 \mu \mathrm{g} / \mathrm{ml})$ on prolactin release induced by various concentrations of TRH was also tested. The effect of annexin 5 blockade on prolactin release was also examined by incubating cells for three hours with dilutions of annexin 5 antiserum from $1: 800$ to $1: 100$. The effect of anti-annexin 5 on TRH stimulated prolactin release was then examined. Pituitary cells were incubated with various concentrations of TRH and anti-annexin $5(1: 200)$ for 30 minutes. Indomethacin is an inhibitor of prostaglandin synthesis, and prostaglandins are also thought to stimulate prolactin release [21]. Thus, indomethacin $(1 \mathrm{mg} / \mathrm{ml})$ was added to medium containing anti-annexin 5 serum $(1: 200)$ and incubated for thirty minutes, to determine if it could reverse anti-annexin 5 augmentation of prolactin release.

\section{Hormone assay}

Prolactin concentration in the culture medium was assayed by time-resolved fluorometric immunoassay using NIDDK rat prolactin assay kit with Delfia system (Perkin Elmer Life Sciences, Tokyo, Japan). Prolactin I-5 was labeled with Europium using a Delfia Eu-labeling kit (Perkin Elmer Life Sciences). Antirabbit gamma globulin goat serum was produced in our laboratory and purified by ammonium sulfate precipitation. An Immunoplate (96 wells, Nunc Co., Japan) was coated with $200 \mu \mathrm{l} /$ well of the anti-rabbit gamma globulin $\operatorname{IgG}(50 \mu \mathrm{g} / \mathrm{ml})$ and then optimally diluted anti-rat prolactin serum (aPRL-S-9) was overlayed. Sample and Eu-labeled hormone were incubated overnight at room temperature and the intensity of bound label was measured with a Delfia research fluorometer. All samples were run in duplicate. 


\section{Statistics}

Multiple comparisons of differences between means were analyzed by one-way ANOVA and the Bonferroni method. $\mathrm{P}$ values less than 0.05 were considered significant.

\section{Results}

As we previously observed that annexin 5 inhibited prolactin release on day 8 of primary culture [14], we first examined the effect of annexin 5 on prolactin release in the same incubation time of three hours. The treatment did not affect prolactin release in the present experimental condition in which all experiments were performed on the second day of primary culture (Fig. 1). On the other hand, in cells cultured for four days, we observed that annexin 5 inhibited basal prolactin release (unpublished data). To evaluate further the inhibitory action of annexin 5 on PRL release, we examined the effect of annexin 5 on TRH stimulated PRL release. While annexin 5 showed no obvious effects on prolactin release during the threehour incubation, annexin $5(1 \mu \mathrm{g} / \mathrm{ml})$ suppressed prolactin release when administered simultaneously with TRH even in thirty minute incubation (Fig. 2). TRH stimulated PRL release in a dose dependent manner and the inhibitory effect of annexin 5 were more apparent at higher doses of TRH. These results indicate that intrinsic annexin 5 is enough to suppress basal PRL secretion but TRH would overcome the effect. To assess the point, we examined the effect of antiannexin 5 on PRL release. Incubation with antiannexin 5 antibody stimulated prolactin release in a dose dependent manner (Fig. 3). Surprisingly, addition of TRH did not stimulate further release of prolactin from cultures treated with anti-annexin 5 (Fig. 4). As TRH stimulates PRL release, at least partly, by increasing lipoxygenase product [22] and annexin 5 is reported to inhibit phospholipase $\mathrm{A}_{2}$ [3], we tested the effect of indomethacin, a cyclooxygenase inhibitor, on anti-annexin 5-stimulated PRL release to see whether constitutive production of prostaglandins is involved in the augmentation of PRL release by anti-annexin 5 . The increase in prolactin release by anti-annexin 5 was effectively suppressed by indomethacin. Indomethacin itself did not show any effect on basal prolactin release (Fig. 5).

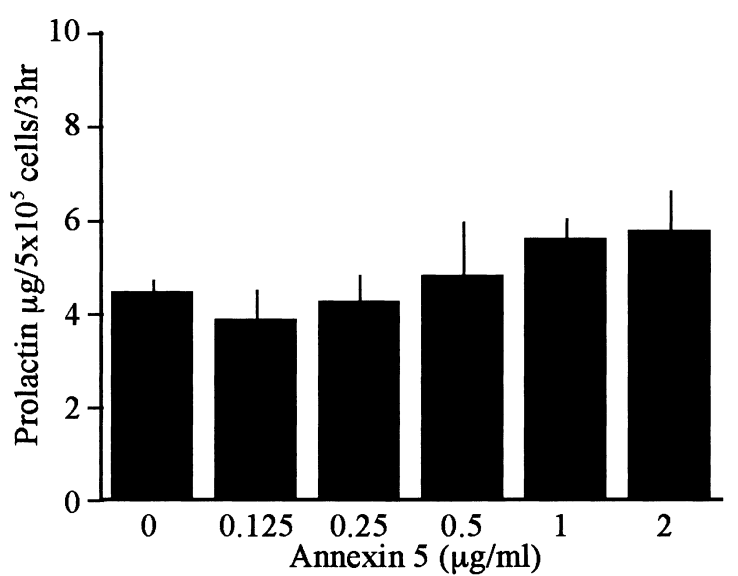

Fig. 1. Effect of annexin 5 on basal release of prolactin. On the day of experiment, cells were preincubated in FCS-free medium for three hours. Various doses of recombinant rat annexin 5 were then administered for three hours. Data are expressed as mean \pm SEM of groups consisting of three observations.

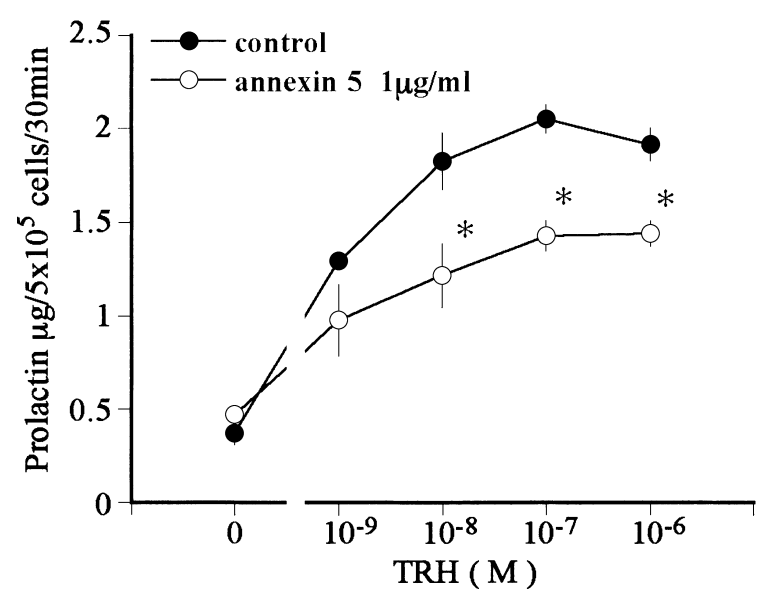

Fig. 2. Effect of annexin 5 on TRH-stimulated prolactin release. Two days after cell dissociation, cells were preincubated in FCS-free medium for three hours. Various doses of TRH were then administered for $30 \mathrm{~min}$. Annexin $5(1 \mu \mathrm{g} / \mathrm{ml})$ was simultaneously added to half of groups. Data are expressed as the mean \pm SEM of groups consisting of three observations. Asterisks reveal significant difference between annexin 5-treated group and control at each TRH concentration $(\mathrm{P}<0.05)$.

\section{Discussion}

It was shown that annexin 5 inhibits TRH-stimulated prolactin release while annexin 5 had no obvious effect on basal PRL release, even if anti-annexin 5 augmented basal prolactin release. Interestingly, we previously showed that annexin 5 inhibited basal PRL release on 


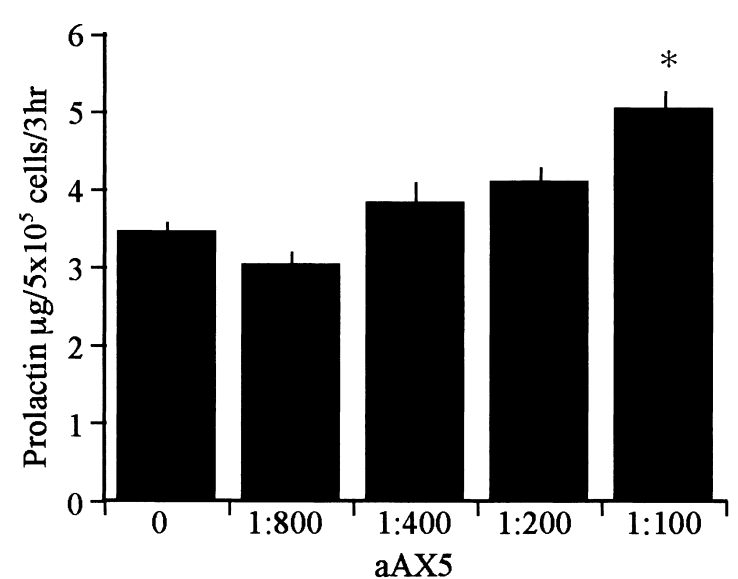

Fig. 3. Effect of anti-annexin 5 antibody on basal prolactin release. Two days after cell dissociation, cells were preincubated in FCS-free medium for three hours. Various dilutions of anti-annexin 5 serum from $1: 800$ to $1: 100$ were then administered for three hours. Data are expressed as the mean \pm SEM of groups consisting of three observations. aAX5: antiannexin 5. Asterisk reveals significant difference from control group $(\mathrm{P}<0.05)$.

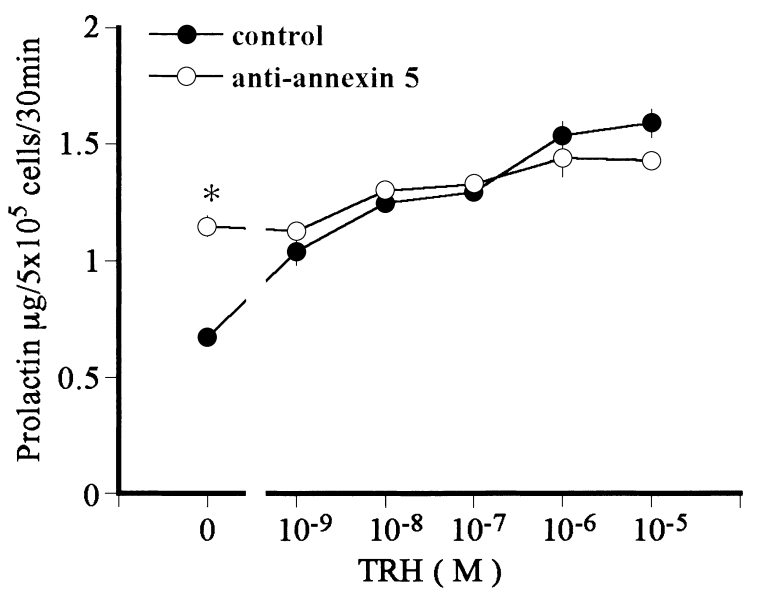

Fig. 4. Effect of anti-annexin 5 on TRH-stimulated prolactin release. Two days after cell dissociation, cells were preincubated in FCS-free medium for three hours. Cells were then treated with various doses of TRH for $30 \mathrm{~min}$. Anti-annexin $5(1: 200)$ was simultaneously added to half of the groups. Data are expressed as mean \pm SEM of groups consisting of three observations. Asterisks reveal significant difference between annexin 5-treated group and control for each TRH concentration $(\mathrm{P}<0.05)$.

the eighth day of primary culture [14]. In the present study, all experiments were carried out after a two-day incubation to shorten experimental period. The inhibitory effect of annexin 5 on basal prolactin release becomes increasingly evident with duration of in vitro culture, suggesting that annexin 5 is counteracting

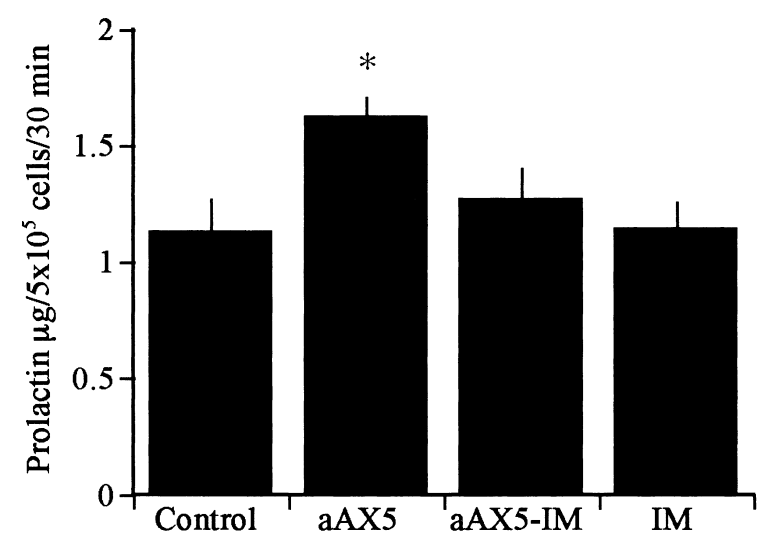

Fig. 5. Suppression of anti-annexin 5-induced increases in prolactin release by indomethacin. Two days after cell dissociation, culture medium was changed and cells were pre-incubated in FCS-free medium for three hours. Anti-annexin $5(1: 200)$, indomethacin $(1 \mu \mathrm{g} / \mathrm{ml})$ or both were then added for thirty minutes. aAX5: antiannexin 5, IM: indomethacin. Asterisks reveal significant difference from control group $(\mathrm{P}<0.05)$.

some factor which is synthesized during a primary culture and favors prolactin release by pituitary cells. It may be eicosanoids, because both cyclooxygenase and lipoxygenase products stimulate prolactin release in culture [21] and constitutive synthesis of eicosanoids in culture is generally observed $[23,24]$.

Annexin 5 supressed TRH augmented PRL release. TRH binds its specific G protein coupled receptor [25] and reportedly signals via the phosphoinositide pathway to downstream effectors thereby inducing prolactin secretion. Although the entire mechanism of prolactin secretion is still obscure, eicosanoids, particularly lipoxygenase products, are reported to be involved in TRH augmentation of prolactin release [22]. On the other hand, annexin family members, including annexin 5, inhibit phospholipase $\mathrm{A}_{2}$ [3]. It is hypothesized that this repression of phospholipase $\mathrm{A}_{2}$ in turn inhibits TRH-augmented eicosanoid synthesis in the present experiment. This idea is compatible with the results revealing that the inhibitory effect of annexin 5 was more apparent at higher doses of TRH. Furthermore, suppression of anti-annexin 5-induced augmentation of prolactin release by indomethacin indicates that there is an inhibition of eicosanoid synthesis by annexin 5 in the culture condition. If annexin 5 suppresses basal synthesis of eicosanoids presumably by inhibiting phospholipase $A_{2}[26,27]$, annexin 5 would also influence the concentration of eicosanoids 
following TRH addition. Although further study is needed to clarify this hypothesis, we suggest that pituitary annexin 5 per se would favor maintaining a local environment by inhibiting eicosanoid synthesis probably through repression of phospholipase $\mathrm{A}_{2}$ activity.

We previously reported that annexin 5 is synthesized by the gonadotropes, and that GnRH stimulates its expression [10-13]. Annexin 5 was shown to stimulate gonadotropin release leading us to propose that annexin 5 is a signal transduction factor downstream of the GnRH receptor $[13,28]$. The results obtained in the present study regarding the effect of annexin 5 on prolactin indicate a different mechanism of action from that seen in the gonadotropes, suggesting that annexin 5 has multiple functions in the anterior pituitary gland. We demonstrated that membrane depolarization by a high concentration of potassium induces externalization of annexin 5 by pituitary cells [20], and although it is unclear how annexin 5 is secreted, the extracellular presence of annexin 5 has been repeatedly reported [3,29]. Thus, cells that secrete annexin 5, most probably gonadotropes, could modulate local eicosanoid concentrations in the pituitary gland thereby suppressing or stimulating prolactin secretion. We hypothesize that annexin 5 is a local regulator of lactrotrope function, a possibility which we are currently investigating in our laboratory. Interestingly, another member of the annexin family proteins, annexin 1 , was shown to be involved in the glucocorticoid inhibition of PRL release induced by cAMP [30]. Annexin 1, however, was not shown to be involved in the inhibition by glucocorticoids on TRH-induced PRL release. These differences indicate a divergence in the mechanism and may reveal specific physiological roles for each annexin.

In summary, the present study demonstrates that pituitary endogenous annexin 5 has an inhibitory effect on prolactin release probably by suppressing eicosanoid synthesis in primary pituitary cell culture. It is suggested that annexin 5 provides a local environment avoring stimulation of prolactin secretion by TRH.

\section{Acknowledgements}

The authors wish to express their appreciation for the gift of rat prolactin assay kit provided by the National Institute of Diabetes and Digestive and Kidney Diseases, the National Hormone and Peptide Program. We are also grateful to Miyoko Nakata for her assistance in manuscript preparation. This work was supported in part by Grants-in-Aid for Scientific Research (No. 14360181 to M.K.) from Japan Society for the Promotion of Science and by a Grant for Scientific Research from Kitasato University, School of Veterinary Medicine and Animal Sciences.

\section{References}

1. Crompton MR, Moss SE, Crumpton MJ (1988) Diversity in the lipocortin/calpactin family. Cell 55: 1-3.

2. Wallner BP, Mattaliano RJ, Hession C, Cate RL, Tizard R, Sinclair LK, Foeller C, Chow EP, Browing JL, Ramachandran KL, et al. (1986) Cloning and expression of human lipocortin, a phospholipase A2 inhibitor with potential anti-inflammatory activity. Nature 320: 77-81.

3. Pepinsky RB, Tizard R, Mattaliano RJ, Sinclair LK, Miller GT, Browning JL, Chow EP, Burne C, Huang KS, Pratt D, Wachter L, Hession C, Frey AZ, Wallner BP (1988) Five distinct calcium and phospholipid binding proteins share homology with lipocortin I. J Biol Chem 263: 10799-10811.

4. Iwasaki A, Suda M, Nakao H, Nagoya T, Saino Y, Arai K, Mizoguchi T, Sato F, Yoshizaki H, Hirata M, et al. (1987) Structure and expression of cDNA for an inhibitor of blood coagulation isolated from human pla- centa: a new lipocortin-like protein. J Biochem (Tokyo) 102: 1261-1273.

5. Shibata S, Sato H, Maki M (1992) Calphobindin I (annexin V) inhibits protein kinase C. Tohoku J Exp Med 166: 479-481.

6. Huber R, Schneider M, Mayr I, Romisch J, Paques EP (1990) The calcium binding sites in human annexin V by crystal structure analysis at 2.0 A resolution. Implications for membrane binding and calcium channel activity. FEBS Lett 275: 15-21.

7. Gerke V, Moss SE (2002) Annexins: from structure to function. Physiol Rev 82: 331-371.

8. Kawaminami M, Tanaka K, Asawa T, Osugi S, Kawauchi H, Kurusu S, Hashimoto I (1992) Association of annexin $\mathrm{V}$ with prolactin in the rat anterior pituitary gland. Biochem Biophys Res Commun 186: 894-898.

9. Saito S, Katayama M, Kurusu S, Kawaminami M, 
Hashimoto I Analysis of annexin 5 expression mechanism in the primary culture of pituitary cells (in Japanese, abstract). Annual meeting of Japanese Society of Animal Reproduction, Tokyo, 1997.

10. Kawaminami M, Yamaguchi K, Miyagawa S, Numazawa S, Ioka H, Kurusu S, Hashimoto I (1998) Ovariectomy enhances the expression and nuclear translocation of annexin 5 in rat anterior pituitary gonadotrophs. Mol Cell Endocrinol 141: 73-78.

11. Kawaminami M, Kawamoto T, Tanabe T, Yamaguchi K, Mutoh K, Kurusu S, Hashimoto I (1998) Immunocytochemical localization of annexin 5, a calciumdependent phospholipid-binding protein, in rat endocrine organs. Cell Tissue Res 292: 85-89.

12. Kawaminami M, Tsuchiyama Y, Saito S, Katayama M, Kurusu S, Hashimoto I (2002) Gonadotropin-releasing hormone stimulates annexin 5 messenger ribonucleic acid expression in the anterior pituitary cells. Biochem Biophys Res Commun 291: 915-920.

13. Kawaminami M, Etoh S, Miyaoka H, Sakai M, Nishida M, Kurusu S, Hashimoto I (2002) Annexin 5 messenger ribonucleic acid expression in pituitary gonadotropes is induced by gonadotropin-releasing hormone $(\mathrm{GnRH})$ and modulates GnRH stimulation of gonadotropin release. Neuroendocrinology 75: 2-11.

14. Kawaminami M, Okazaki K, Uchida S, Marumoto N, Takehara K, Kurusu S, Hashimoto I, Walker AM (1996) Intrapituitary distribution and effects of annexin 5 on prolactin release. Endocrine 5: 9-14.

15. Ben-Jonathan N, Hnasko R (2001) Dopamine as a prolactin (PRL) inhibitor. Endocr Rev 22: 724-763.

16. Kordon C, Drouva SV, Martinez de la Escalera G, Weiner RI (1994) Role of classic and peptide neuromediators in the neuroendocrine regulation of luteinizing hormone and prolactin. In: Knobil E, Neill JD (eds) The Physiology of Reproduction. Raven Press, New York, 1621-1681.

17. Smith MS, Freeman ME, Neill JD (1975) The control of progesterone secretion during the estrous cycle and early pseudopregnancy in the rat: prolactin, gonadotropin and steroid levels associated with rescue of the corpus luteum of pseudopregnancy. Endocrinology 96: 219-226.

18. Shin SH, Papas S, Obonsawin MC (1987) Current status of the rat prolactin releasing factor. Can J Physiol Pharmacol 65: 2036-2043.

19. Takehara K, Uchida S, Marumoto N, Asawa T, Osugi S, Kurusu S, Hashimoto I, Kawaminami M (1994) Secretion of recombinant rat annexin 5 by insect cells in a baculovirus expression system. Biochem Biophys Res Commun 200: 1421-1427.
20. Kawaminami M, Uchida S, Marumoto N, Naito K, Okazaki K, Sato Y, Kurusu S, Hashimoto I, Mutoh K-I, Walker AM (1994) Stimulation of secretion by membrane depolarization increases extracellular plasma membrane association of annexin 5 in the anterior pituitary gland. Endocrine 2: 357-362.

21. Gautvik KM, Kriz M (1976) Effects of prostaglandins on prolactin and growth hormone synthesis and secretion in cultured rat pituitary cells. Endocrinology 98 352-358.

22. Canonico PL, Schettini G, Valdenegro CA, MacLeod RM (1983) Arachidonic acid metabolism and prolactin secretion in vitro: a possible role for the lipoxygenase products. Neuroendocrinology 37: 212-217.

23. Koike K, Hirota K, Ohmichi M, Kadowaki K, Ikegami H, Yamaguchi M, Miyake A, Tanizawa O (1991) Tumor necrosis factor-alpha increases release of arachidonate and prolactin from rat anterior pituitary cells. Endocrinology 128: 2791-2798.

24. Dartois E, Bouton MM (1986) Role of calcium on TPA-induced secretion of ACTH and PGE2 by pituitary cells: effect of dexamethasone. Biochem Biophys Res Commun 138: 323-329.

25. McIntosh RP, Catt KJ (1987) Coupling of inositol phospholipid hydrolysis to peptide hormone receptors expressed from adrenal and pituitary mRNA in Xenopus laevis oocytes. Proc Natl Acad Sci USA 84: 90459048.

26. Buckland AG, Wilton DC (1998) Inhibition of secreted phospholipases A2 by annexin V. Competition for anionic phospholipid interfaces allows an assessment of the relative interfacial affinities of secreted phospholipases A2. Biochim Biophys Acta 1391: 367-376.

27. Buckland AG, Wilton DC (1998) Inhibition of human cytosolic phospholipase A2 by human annexin V. Biochem J 329: 369-372.

28. Kawaminami M, Shibata Y, Yaji A, Kurusu S, Hashimoto I (2003) Prolactin inhibits annexin 5 expression and apoptosis in the corpus luteum of pseudopregnant rats: involvement of local gonadotropinreleasing hormone. Endocrinology 144: 3625-3631.

29. Christmas P, Callaway J, Fallon J, Jones J, Haigler HT (1991) Selective secretion of annexin 1, a protein without a signal sequence, by the human prostate gland. J Biol Chem 266: 2499-2507.

30. Taylor AD, Philip JG, John CD, Cover PO, Morris JF, Flower RJ, Buckingham JC (2000) Annexin 1 (lipocortin 1) mediates the glucocorticoid inhibition of cyclic adenosine 3',5'-monophosphate-stimulated prolactin secretion. Endocrinology 141: 2209-2219. 